\title{
O Direito à Moradia: Reflexões sobre Habitabilidade e Dignidade
}

\author{
Mary Jane Paris Spink ${ }^{1}$ \\ Sandra Luzia Assis Silva ${ }^{1}$ \\ ${ }^{1}$ Pontifícia Universidade Católica de São Paulo, SP, Brasil. $\quad$ 'Pontifícia Universidade Católica de São Paulo, SP, Brasil. \\ Mário Henrique da Mata Martins² \\ Simone Borges da Silva ${ }^{3}$ \\ ${ }^{2}$ Fundação Getulio Vargas, SP, Brasil. \\ ${ }^{3}$ Associação Saúde da Família, SP, Brasil.
}

\begin{abstract}
Resumo: Com base no pressuposto de que o direito à moradia é um princípio básico estabelecido em tratados internacionais e na própria Constituição brasileira, este ensaio tem três objetivos: situar historicamente a introdução deste princípio no contexto internacional e nacional; sua reelaboração a partir do conceito de adequação habitacional e a translação, no contexto brasileiro, da discussão sobre moradia adequada para moradia digna. Com este intuito, foram analisados documentos considerados centrais nesse debate, tendo como ponto de partida a Declaração de Direitos Humanos de 1948. Como método, a discussão está assentada na análise de documentos de domínio público e pautada na perspectiva da psicologia social discursiva. Como conclusão, consideramos que a translação de moradia adequada para moradia digna tem por base situar o direito à moradia como exercício de cidadania, com o uso de moradia digna para indicar que o que está em pauta é a possibilidade de ter uma vida digna.
\end{abstract}

Palavras-chave: Direito à Moradia, Moradia Adequada, Dignidade, Direitos Humanos.

\section{The Right to Adequate Housing: Considerations about Habitability and Dignity}

\begin{abstract}
Starting from the premise that the right to adequate housing is a basic principle established in international treaties as well as in the Brazilian Constitution, the aim of this essay is threefold: to trace the introduction of this principle in the international and national contexts; to follow its further elaboration in debates on adequate housing and to examine the translation of the term "adequate housing" into "dignified housing" in Brazilian Portuguese. National and international documents that are considered central to this debate were analyzed, taking as a starting point the United Nation's 1948 Declaration of Human Rights. Methodologically, the analysis is based on discursive social psychology discussion of the characteristics of public domain documents. We conclude that the translation of adequate housing to dignified housing, in Brazil, is the result of placing the right to a house as an exercise in citizenship, with the use of the expression dignified housing serving to indicate that what is at stake is the dignity of life itself.
\end{abstract}

Keywords: Housing as a Right, Adequate Housing, Dignity, Human Rights.

\section{El Derecho a la Vivienda: Reflexiones sobre Habitabilidad y Dignidad}

Resumen: Con base en el supuesto de que el derecho a la vivienda es un principio básico establecido por tratados internacionales y por la propia Constitución brasileña, este ensayo tiene tres objetivos: situar históricamente la introducción de este principio en el contexto internacional y nacional; su reelaboración a partir del concepto de adecuación habitacional y la traslación, en el contexto brasileño, de la discusión sobre vivienda adecuada para vivienda 
digna. Con este propósito, se analizaron documentos considerados centrales en ese debate, teniendo como punto de partida la Declaración de Derechos Humanos de 1948. La discusión está asentada en el análisis de documentos de dominio público y pautada en la perspectiva de la psicología social discursiva. Concluimos que la traslación de vivienda adecuada para vivienda digna tiene por base situar el derecho a la vivienda como ejercicio de la ciudadanía, con el uso de vivienda digna para indicar que lo que está en pauta es la posibilidad de tener una vida digna.

Palabras clave: Derecho a la Vivienda, Vivienda Adecuada, Dignidad, Derechos Humanos.

\section{Introdução}

Recentemente, a discussão sobre o direito à moradia no contexto do déficit habitacional se tornou midiática diante da tragédia do Edifício Wilton Paes de Almeida, no Largo do Paissandu em São Paulo. Nessa ocasião, no dia 10 de maio de 2018 , houve um incêndio de grandes proporções seguido de desmoronamento. O prédio havia sido ocupado e nele habitavam 116 famílias, de acordo com o cadastro da Prefeitura Municipal de São Paulo. Após o desastre, elas foram alojadas em barracas próximas ao local, cercadas por uma grade de metal e, até a presente data, aguardam ao relento um novo lugar para morar.

Poucos meses antes do desabamento, a socióloga Lidiane Maciel (O Globo, 2018) havia iniciado um estudo sobre o perfil populacional dessas famílias. Após a tragédia, ela divulgou fotografias das áreas internas do prédio e do cotidiano dos moradores em suas redes sociais e chamou atenção para diferentes aspectos da vida nesse edifício. Paredes rachadas eram cobertas com tapumes de madeira, portas eram improvisadas com panos para separar os ambientes e a proibição de uso de equipamentos que apresentassem risco de incêndio era uma forma de lidar com a precariedade das instalações elétricas. Em meio a essa situação, as regras de convivência e circulação e a decoração de alguns andares com plantas e pôsteres revelam uma forma de morar que não estava restrita apenas à existência de um abrigo, evidentemente precário e perigoso, mas à produção do espaço para torná-lo habitável.

Esse ponto nos chamou atenção. Enquanto as reportagens e estudos sobre o direito à moradia tendem a partir do pressuposto de que esta é um objeto de posse e focam na desigualdade da distribuição habitacional brasileira, no déficit habitacional, nos programas de construção de moradia social e na ocupação de terrenos e construções, nos propomos, neste ensaio, a discutir a moradia na perspectiva da habitabilidade.

É importante destacar que essa proposta não é nova na psicologia. Do ponto de vista histórico, os psicólogos e as psicólogas adentram essa seara na primeira metade do século XX em virtude de uma demanda social particularmente europeia: a necessidade de reconstruir os ambientes assolados pelos bombardeios da Segunda Guerra Mundial. Essa demanda exigiu que arquitetos e engenheiros buscassem compreender a relação entre o comportamento humano e o espaço físico para planejar da melhor maneira possível a restauração das cidades. Para isso, convocaram profissionais da psicologia que, naquela época, ainda não haviam se debruçado sistematicamente sobre questões relativas à habitação. Isso impulsionou a pesquisa na área e promoveu o nascimento de perspectivas psicológicas com foco na relação pessoa-ambiente (Castro, 2005; Ferreira, 2004).

Uma dessas perspectivas foi denominada de psicologia da habitação e buscava compreender a reação dos moradores a fatores específicos, como uso dos espaços cobertos com vistas a garantir a privacidade, influência da luz e do barulho nos estados emocionais e os valores estéticos para a moradia. A meta desses estudos era acessar e até certo ponto medir a reação das pessoas às condições de habitabilidade de determinada construção. Essas pesquisas foram fundamentais para que a psicologia desde os primeiros passos para produzir conhecimento científico sobre as formas de habitar (Chapin, 1951).

Atualmente, o diálogo da psicologia com as políticas habitacionais evoluiu e tem ocorrido de múltiplas formas: com a criação de tipologias que expressam a relação de apego à moradia (Rabinovich \& Carvalho, 2001), para explicitar as necessidades psicológicas dos moradores e garantir seu bem-estar habitacional (Bernard, 2005), para ressignificar a moradia como um ponto de referência que possibilita às pessoas habitarem a cidade (Franco \& Van Stralen, 2012) ou mesmo como uma sensibilização frente aos modos de viver e morar periféricos por meio da participação no cotidiano de seus moradores (Spink, 2018). Embora distintas, as pesquisas 
compartilham entre si o reconhecimento dos interlocutores como sujeitos de direitos, ativos no processo de produzir sua moradia, seja simbolicamente, materialmente ou discursivamente.

Neste ensaio, destacamos que a participação dos moradores na produção do espaço depende da maneira como a legislação e os governantes passam a definir as possibilidades de morar, o que restringe as formas de apropriação do espaço.

Apropriar-se do espaço é estabelecer uma relação entre esse espaço e o eu (torná-lo próprio) por meio de um conjunto de práticas. Trata-se de atribuir significação a um lugar; isso pode ser feito no nível da semântica, por meio das palavras e pelos objetos e símbolos que lhes são vinculados (Segaud, 2016, p. 126).

Logo a linguagem, especialmente a jurídica, tem importância central nesse processo. Por esse motivo consideramos necessário complementar essas discussões com um estudo que mostre as ressignificações e os deslizes semânticos do direito à moradia, considerado fundamental desde a promulgação da Declaração dos Direitos Humanos (Nações Unidas, 1948) até a aprovação da Constituição Federal (Brasil, 1988).

Para isso, utilizamos o conceito de translação, aplicado nos estudos sobre ciência, tecnologia e sociedade para expressar o processo por meio do qual uma rede de elementos e práticas é representada. Esse processo é composto de quatro etapas: a problematização (como algo se torna indispensável), o interessamento (como os interesses são alinhados), a coordenação dos papéis (como se define e atribuem papéis a serem desempenhados) e a mobilização (como se produz representatividade para que a representação seja efetivada). Neste artigo, fazemos uma apropriação discursiva do conceito para a análise que realizamos dos documentos, que passam a ser compreendidos como práticas discursivas de legitimação e circulação de conteúdos sobre moradia (Spink, Ribeiro, Conejo, \& Souza, 2014).

Como o direito à moradia passou por amplas reformulações discursivas nas legislações e aplicações das leis, este trabalho enfoca a tensão entre dois qualificadores específicos: a discussão sobre o conceito de moradia adequada no discurso internacional e nacional, e o desenvolvimento do conceito de moradia digna no discurso nacional.

\section{Método}

Faremos isso atentando, em um primeiro momento, para tratados internacionais. Em seguida, focalizaremos as leis e programas nacionais e, por fim, discutiremos a emergência dessa versão de moradia pautada no discurso sobre dignidade no contexto brasileiro. Como breve nota metodológica, vale pontuar que esta discussão está assentada na análise de documentos de domínio público (Spink et al., 2014) que, no cenário internacional e nacional, fornecem os subsídios para as políticas de habitação de interesse social. Os documentos analisados estão apresentados em cada seção deste ensaio e são discutidos a partir de uma perspectiva discursiva.

\section{Resultados}

\section{O direito à moradia}

Há vários passos na construção deste conceito. Certamente, o primeiro é a própria criação das Nações Unidas após a Segunda Guerra Mundial, que teve como primeira etapa a assinatura de seu estatuto, a Carta das Nações Unidas (Charter of The United Nations), em 26 de junho de 1945, em São Francisco, no encerramento da Conferência das Nações Unidas sobre Organização Internacional (United Nations Conference on International Organization) (United Nations, 1945).

Este estatuto está no centro de toda a ação desenvolvida pelas Nações Unidas no domínio da proteção e promoção dos direitos e das liberdades fundamentais, sobretudo na elaboração de três documentos: a Declaração Universal dos Direitos Humanos (Nações Unidas, 1948); o Pacto Internacional sobre os Direitos Económicos, Sociais e Culturais das Nações Unidas, de 1966; e o Pacto Internacional sobre os Direitos Civis e Políticos das Nações Unidas, também de 1966, cuja promulgação no Brasil ocorreu em 1992 (Brasil, 1992).

Estes três instrumentos definem e consagram os direitos humanos e as liberdades fundamentais. Constituem a base de mais de cinquenta outras convenções, declarações, conjuntos de regras e de princípios adaptados pela Organização das Nações Unidas. Contudo o direito à moradia é formulado em dois desses documentos, e estes, portanto, serão aqui discutidos: a Declaração dos Direitos Humanos (DUHD) e o Pacto Internacional sobre os Direitos Econômicos, Sociais e Culturais das Nações Unidas. 


\section{A Declaração Universal dos Direitos Humanos (DUDH)}

Segundo James Spickard (2017), dois anos depois da criação da Organização das Nações Unidas (ONU), em 1945, o primeiro secretário-geral, Trygve Lie, iniciou a preparação da DUDH passando esta tarefa à Divisão sobre Direitos Humanos, cujo diretor era o canadense John Peters Humphrey. Inicialmente, a Divisão tinha dezoito membros e, três anos mais tarde, juntaram-se a eles P. C. Chang, René Cassin e Jacques Maritain. Formou-se então a Comissão de Direitos Humanos, presidida por Eleanor Roosevelt. Esses intelectuais tinham o desafio de respeitar as sensibilidades culturais das 56 nações que constituíam a ONU naquela data. Em 10 de dezembro de 1948, a DUDH foi aprovada por 46 nações com oito abstenções. Para evitar confrontos culturais, foi escolhido o termo "pessoa", seguindo o pensamento de Jacques Maritain.

Em 1949, foram publicados os Anais do simpósio organizado pela Unesco que inclui os textos de vários especialistas consultados para elaboração da DUDH (Unesco, 1949). O livro compreende três anexos: o anexo I contém o memorando e o questionário enviado a especialistas de todo o mundo sobre o tema dos direitos humanos; o anexo II relata o caminho percorrido para elaboração de uma declaração passível de ser aceita por todas as nações, apesar das diferenças culturais existentes e inclui, como síntese, quinze direitos aceitos por todos, a despeito de possíveis diferenças culturais; e o anexo III, que é a própria declaração.

Nos dois primeiros anexos, há um histórico sobre a trajetória dos direitos humanos no ocidente considerando dois momentos. O primeiro concerne à formulação dos direitos civis e políticos no século XVIII, histórico que embasou a elaboração do Pacto Internacional sobre os Direitos Civis e Políticos. O segundo momento decorre dos avanços tecnológicos e industriais, análise que levou à formulação dos direitos econômicos e sociais que, por sua vez, deu origem ao Pacto Internacional sobre os Direitos Econômicos, Sociais e Culturais. A elaboração dos dois pactos data do simpósio realizado em Paris em 1947, porém foi apenas em 1966 que foram abertos para assinatura.

Na Declaração Universal dos Direitos Humanos, o direito à moradia é enunciado no parágrafo 1 do artigo $25^{\circ}$ :

Toda pessoa tem direito a um padrão de vida capaz de assegurar a si e a sua família saúde e bem-estar, inclusive alimentação, vestuário, habitação, cuidados médicos e os serviços sociais indispensáveis, e direito à segurança em caso de desemprego, doença, invalidez, viuvez, velhice ou outros casos de perda dos meios de subsistência fora de seu controle (Nações Unidas, 1948, p. 1, tradução nossa).

Nessa etapa, faz-se referência a condições adequadas de vida, nas quais se inclui a questão da moradia adequada. Todavia o sentido de adequação utilizado internacionalmente só virá a se estabelecer no futuro. No Anexo II dos Anais referidos, foi incluída uma síntese dos direitos fundamentais que o Comitê sobre Princípios Filosóficos do Direito do Homem da Organização das Nações Unidas para a Educação, a Ciência e a Cultura (Unesco) considerou como aceitos por todos. Dentre os quinze direitos listados, o de número cinco se refere ao direito à propriedade: "Todo homem tem direito à propriedade privada, na medida em que seja necessário para seu uso pessoal e para o uso de sua família; nenhuma outra forma de propriedade é em si um direito fundamental" (United Nations Educational and Cultural Organization, 1949, p. 269, tradução nossa).

\section{O Pacto Internacional sobre os Direitos Econômicos, Sociais e Culturais das Nações Unidas (1966/1976)}

Em 1966, foi aprovado o Pacto Internacional de Direitos Econômicos, Sociais e Culturais que, em seu artigo 11, parágrafo 1, dá mais substância ao direito à habitação, estabelecendo que "Os Estados Partes no presente Pacto reconhecem o direito de todas as pessoas a um nível de vida suficiente para si e para as suas famílias, incluindo alimentação, vestuário e moradia suficientes, bem como a um melhoramento constante das suas condições de existência" (Brasil, 1992). Note que o termo utilizado é moradia (housing), que passa a ser qualificada com o adjetivo adequate, traduzida por "adequada" quando promulgada no Brasil (Brasil, 1992).

\section{Sobre o direito à moradia nos textos nacionais}

No Brasil, o direito à moradia é garantido no artigo $6^{\circ}$ da Constituição brasileira, cuja redação foi alterada pela Emenda Constitucional no 90 , de 2015: 
"São direitos sociais a educação, a saúde, a alimentação, o trabalho, a moradia, o transporte, o lazer, a segurança, a previdência social, a proteção à maternidade e à infância, a assistência aos desamparados, na forma desta Constituição" (Brasil, 1988, p. 18).

Porém uma política nacional de habitação congruente com os tratados e pactos internacionais apenas será viabilizada na década de 2000. Nesse meio tempo, como ocorreu em outros países, a questão da moradia para as classes pobres foi alvo de ações higienistas, sobretudo por meio de projetos de urbanização com exclusão dos mais pobres e de propostas voltadas à construção de moradias populares. Segundo Rubin e Bolfe (2014), fazem parte destas experiências: os projetos desenvolvidos pelos Institutos de Aposentadoria e Pensões (IAPs), a Fundação da Casa Popular e a criação do Banco Nacional de Habitação.

De acordo com a revisão histórica da política habitacional de autoria de Nabil Bonduki (2015), a partir do governo Fernando Henrique Cardoso FHC (1995-2002), passam a ser adotados pressupostos diversos daqueles que vigoravam desde o período em que o foco dos programas habitacionais era o Banco Nacional de Habitação. No governo FHC, a Secretaria de Política Urbana passou a gerir o setor habitacional participando, por exemplo, das discussões preparatórias para a segunda Conferência das Nações Unidas para os Assentamentos Urbanos, a Habitat II.

Marco importante do governo FHC foi a promulgação do Estatuto da Cidade, em 2001, pela Lei Federal $\mathrm{n}^{\circ} 10.257$, que estabeleceu princípios e diretrizes para o ordenamento territorial e urbanístico, calcado no princípio da função social e ambiental da propriedade e na garantia do Direito a Cidades Sustentáveis, "entendido como o direito à terra urbana, à moradia, ao saneamento ambiental, à infraestrutura urbana, ao transporte e aos serviços públicos, ao trabalho e ao lazer, para as presentes e futuras gerações" (Brasil, 2001, Art. $2^{\circ}$, inciso I). Essa lei também estabelece uma diversidade de instrumentos que tratam da segurança da posse (Usucapião Urbano, Concessão do Direito Real de Uso e Zonas Especiais de Interesse Social), da regularização fundiária em Zonas de Especial Interesse Social (Zeis), do ordenamento territorial (plano diretor participativo, parcelamento, edificação ou utilização compulsórios).

Porém, como veremos a seguir, a incorporação plena do direito à moradia é proposta do governo petista de Luiz Inácio Lula da Silva (2003-2010) e tem como antecedente a elaboração do Projeto Moradia (Instituto Cidadania, 2000), que será discutido ao focalizarmos o uso da expressão "moradia digna" em documentos referentes às políticas voltadas para moradias de interesse social.

Em 2003, no início do governo de Lula, foi criado o Ministério das Cidades, cujo foco principal é a inclusão dos setores excluídos do direito à cidade, já que a habitação e o acesso aos serviços básicos são fundamentais para a cidadania. Em 2005, a Lei no 11.124 (Brasil, 2005), de iniciativa popular, cria o Sistema Nacional de Habitação de Interesse Social (SNHIS) e o Fundo Nacional de Habitação de Interesse Social (FNHIS), com o objetivo de promover o acesso à terra urbanizada e à habitação digna para a população de menor renda (Art. $2^{\circ}$ - incisos I e II), acolhendo o princípio da moradia digna como um vetor de inclusão social (Art. $4^{\mathrm{o}}$ - inciso I - item b). Vale apontar que é nessa lei a primeira menção a moradia digna no Brasil, embora, como veremos adiante, não há nela definição do que seria uma moradia digna.

A Secretaria Nacional de Habitação do Ministério das Cidades coordenou a elaboração do Plano Nacional de Habitação (PlanHab), um dos mais importantes instrumentos para a implementação da nova Política Nacional de Habitação (PNH), prevista na Lei $\mathrm{n}^{\circ}$ 11.124/2005 que estruturou o Sistema Nacional de Habitação de Interesse Social (SNHIS). O processo participativo foi um dos pilares constitutivos do PlanHab. Ao longo de sua elaboração, a Secretaria Nacional de Habitação buscou consolidar um amplo pacto nacional para a garantia do direito à moradia. Foram organizados diversos debates regionais e setoriais, envolvendo especialmente o acompanhamento direto dos representantes do Conselho das Cidades e do Conselho Gestor do Fundo Nacional de Habitação de Interesse Social (CGFNHIS). Essas diversas instâncias de participação foram importantes espaços de interlocução política, proposição e deliberação.

Depois de finalizada a consultoria do Consórcio PlanHab, formado para a elaboração do plano, um conjunto de mudanças no cenário nacional impactou diretamente o setor habitacional. As mudanças estruturais observadas no cenário macroeconômico brasileiro, tais como a melhoria de renda da população, as recentes ações implementadas pelo Governo Federal para mitigar os efeitos da crise financeira internacional na economia doméstica e a elevação expressiva do volume de crédito e dos investimentos no setor 
habitacional desenharam um cenário propício para garantir o sucesso de uma política habitacional de longo prazo, especialmente voltada para a baixa renda.

Nesse sentido, o PlanHab é parte de um processo de planejamento de longo prazo para o setor habitacional, que pressupõe revisões periódicas e articulação com outros instrumentos de planejamento orçamentário-financeiro do Governo Federal, como os planos plurianuais, permitindo que suas metas de produção física e de avanços institucionais possam estar associadas ao planejamento dos recursos necessários para sua cobertura e tendo o ano de 2023 como horizonte final para elaborar estratégias e propostas. Com ele, pretende-se implementar um conjunto de ações capazes de construir um caminho que permita avançar no sentido de atingir o principal objetivo da PNH: universalizar o acesso à moradia para todo cidadão brasileiro.

\section{Do direito à moradia ao conceito de moradia adequada}

A introdução do conceito de moradia adequada segue caminho um pouco distinto daquele que instituiu a moradia como direito humano básico. Seja na esfera internacional, seja no âmbito nacional, o direito à moradia foi estabelecido como premissa no contexto de declarações e leis e, obviamente, de programas que tinham como objetivo tornar esse direito um fato.

São outros os caminhos que levam a introduzir que não basta garantir um teto, mas que a moradia tenha condições de habitabilidade - condições estas que extrapolam a construção propriamente dita e ampliam a adequação para um contexto mais amplo como discutiremos a seguir.

Sem propor que os desdobramentos em âmbito nacional sejam réplicas ou espelhamento de tratados internacionais, partimos do pressuposto de que, sendo o Brasil signatário de muitos desses tratados, há uma convergência - ou melhor - uma retroalimentação entre esferas de discussão locais e globais. Igualmente, sem pretender que há uma ordem cronológica ou hierárquica que amarra acontecimentos no cenário internacional e nacional, iniciamos, por conveniência, situando a questão no cenário internacional para depois abordá-la no cenário nacional.

\section{O cenário internacional}

Em 1976, foi realizada em Vancouver, no Canadá, a Conferência sobre Assentamentos Humanos que deu origem, em 1978, ao Programa das Nações Unidas para Assentamentos Humanos (UN-Habitat). Consta das recomendações de Vancouver a afirmação que "abrigo" (shelter) e serviços adequados constituem um direito humano básico. Não há menção ao termo "moradia", talvez porque seja função do UN-Habitat problematizar a questão maior dos assentamentos humanos (United Nations, 2009).

Dez anos mais tarde, o estabelecimento do Ano Internacional dos Desabrigados, em 1987, teve papel relevante na sensibilização da opinião pública para a questão da habitação. Decorre das atividades do Ano, a elaboração da Estratégia Global para o Abrigo para o Ano 2000. Neste enquadre, a noção de "habitação adequada" é introduzida e definida como compreendendo: intimidade suficiente, espaço apropriado, segurança adequada, iluminação e ventilação suficientes, infraestruturas básicas e localização adequadas relativamente ao local de trabalho e aos serviços essenciais (United Nations, 2009).

Esse conceito passará a fazer parte dos documentos elaborados pelo UN-Habitat com a publicação do Comentário Geral no 4 sobre moradia adequada, elaborado pelo Escritório do Alto Comissariado das Nações Unidas para os direitos Humanos (United Nations, 1991) juntamente com o UN-Habitat. Nele são definidos sete componentes básicos para uma moradia adequada: segurança quanto ao direito de propriedade, disponibilidade de serviços, equipamentos e infraestrutura, disponibilidade a preços acessíveis (affordability), habitabilidade; acessibilidade a todos os grupos sociais, localização (acesso a emprego, saúde e equipamentos sociais) e, adequação cultural.

Esses aspectos passam a integrar a noção de moradia adequada, como pode ser visto na Ficha Informativa Sobre Direitos Humanos no 21 (United Nations, 2009). Nesse documento consta o alerta de que o direito à moradia adequada não deve ser interpretado de forma restrita.

Moradia adequada deve prover mais do que quatro paredes e um teto. Várias condições têm que ser observadas para que tipos específicos de abrigo possam ser considerados como "moradia adequada". Esses elementos são tão fundamentais quanto o suprimento e disponibilidade de moradias (United Nations, 2009, p. 3, tradução nossa).

Este ainda é o documento central da discussão sobre moradia adequada, embora tenham sido 
publicadas diversas resoluções desde então que tangenciam o problema da habitação. A Ficha 21 tem por base os documentos internacionais que, em seu conjunto, abordam os fundamentos e implicações do direito à habitação adequada, com especial referência à Declaração Universal sobre dos Direitos Humanos, de 1948, e ao Pacto Internacional de Direitos Econômicos, Sociais e Culturais, de 1966, conforme já discutido.

Essa ficha foi traduzida em várias línguas e é interessante observar a variação das traduções do termo inglês adequate housing. em francês, é traduzido como logement convenable, em espanhol, como vivenda adequada e, em português de Portugal, como moradia condigna. Note-se que a única que diverge das demais é a tradução para o português de Portugal, cujo significado usual se relaciona ao merecimento, ao recebimento de algo justo. Todavia a definição do termo na legislação não expressa esse sentido, aproximando-se à ideia de adequado.

Consta na Ficha 21 uma definição mais precisa sobre os sete componentes básicos relacionados com o direito a uma habitação adequada, conforme disposto no Quadro 1.

\section{Quadro 1}

Definições dos fatores relacionados à habitação condigna.

\begin{tabular}{ll}
\hline Elementos & Definições \\
\hline $\begin{array}{l}\text { Segurança legal } \\
\text { da ocupação }\end{array}$ & $\begin{array}{l}\text { A habitação não será adequada } \\
\text { se seus ocupantes não tiverem } \\
\text { garantias legais de posse. Refere- } \\
\text { se precisamente à proteção legal } \\
\text { contra despejos forçados, assédios } \\
\text { e outras ameaças. }\end{array}$ \\
$\begin{array}{ll}\text { Disponibilidadere-se às condições } \\
\text { de recursos }\end{array}$ & $\begin{array}{l}\text { mínimas de permanência } \\
\text { dos ocupantes na habitação, } \\
\text { como acesso à água potável, } \\
\text { saneamento adequado, energia } \\
\text { para cozinhar, aquecimento, } \\
\text { iluminação, armazenamento de } \\
\text { alimentos e descarte de lixo. } \\
\text { Refere-se aos aspectos relativos } \\
\text { econômica }\end{array}$ \\
$\begin{array}{l}\text { ao custo da habitação, que não } \\
\text { deve ameaçar ou comprometer } \\
\text { os demais direitos humanos dos } \\
\text { ocupantes. } \\
\text { Refere-se às garantias de } \\
\text { segurança física e proteção } \\
\text { contra calor, chuva, frio e riscos } \\
\text { decorrentes de problemas } \\
\text { estruturais e vetores de doenças. }\end{array}$ \\
\hline
\end{tabular}

continua..

\begin{tabular}{|c|c|}
\hline Elementos & Definições \\
\hline $\begin{array}{l}\text { Facilidade de } \\
\text { acesso a grupos } \\
\text { vulneráveis }\end{array}$ & $\begin{array}{l}\text { Refere-se à facilidade de acesso } \\
\text { por pessoas idosas, crianças, } \\
\text { doentes crônicos, vítimas de } \\
\text { catástrofes naturais, entre outros. }\end{array}$ \\
\hline Localização & $\begin{array}{l}\text { Refere-se à possibilidade de } \\
\text { acesso aos locais de trabalho } \\
\text { e oportunidades de emprego, } \\
\text { serviços de saúde, escolas, } \\
\text { creches e outras instalações } \\
\text { sociais. Além disso, habitações } \\
\text { localizadas em locais poluídos } \\
\text { ou áreas perigosas não são } \\
\text { consideradas adequadas, de } \\
\text { acordo com esse critério. }\end{array}$ \\
\hline $\begin{array}{l}\text { Respeito ao } \\
\text { ambiente } \\
\text { cultural }\end{array}$ & $\begin{array}{l}\text { Refere-se ao projeto } \\
\text { arquitetônico que deve ser } \\
\text { formulado para expressar a } \\
\text { identidade e diversidade da } \\
\text { cultural dos ocupantes. }\end{array}$ \\
\hline
\end{tabular}

Fonte: Adaptado de United Nations (2009).

Outras esferas de atuação também vêm contribuindo para alicerçar o conceito de moradia adequada, entre eles os levantamentos sobre a relação entre adequação da moradia e indicadores de saúde, como apresentado no relatório WHO-Europe do Centro Europeu de Ambiente e Saúde publicado em 2004 (World Health Organization, 2004).

O documento fornece uma visão geral do consórcio de instituições de pesquisa estabelecido pela Organização Mundial de Saúde para trabalhar na área de moradia e saúde. A síntese das evidências apresentadas no relatório incorpora também evidências derivadas de um survey pan-europeu sobre o tema. O objetivo do relatório era fornecer evidências científicas para definir prioridades ao nível internacional e local, identificando grupos de risco e provendo melhorias na regulação de edificações e controle de moradias. Toma por base as características de "abrigo adequado" definidas pela UN-Habitat na Declaração de Istambul em 1996, por serem compatíveis com a definição de moradia saudável.

Abrigo adequado significa mais do que ter um teto sobre nossa cabeça. Significa, também, privacidade adequada; espaço adequado; acessibilidade física; segurança adequada; segurança de posse; estabilidade estrutural e durabilidade; iluminação adequada; aquecimento e ventilação; infraestrutura básica adequada, tal como 
suprimento de água, facilidades sanitárias e de gerenciamento de resíduos; qualidade ambiental e fatores associados à saúde apropriados; e localização adequada e acessível em relação ao local de trabalho e suprimentos básicos; todos eles disponíveis e com um custo acessível. O que é adequado deveria ser definido juntamente com as pessoas envolvidas, levando em conta $\mathrm{o}$ a perspectiva de um desenvolvimento gradual.

Frequentemente, o que é adequado varia de país para país uma vez que depende de fatores culturais, sociais, ambientai e econômicos específicos. Fatores relacionados a gênero e idade, tais como a exposição de mulheres e crianças a substâncias tóxicas, deveriam ser consideradas neste contexto (World Health Organization, 2004, p. 1, tradução nossa).

No documento, são considerados vários aspectos que fazem da casa uma moradia saudável: 1) aspectos psicossociais (proteção, laços sociais, identidade, vínculos, satisfação urbana/ambiental, segurança diante do medo de crime);2) aspectos físicos (acessibilidade, conforto térmico, qualidade interna do ar, acidentes domésticos decorrentes de desenho e falta de manutenção, crescimento de fungos); e 3) efeitos na saúde (problemas mentais, distúrbios do sono). Em suma:

Uma moradia pensada apenas como proteção do mundo externo se tornaria um tipo de prisão, uma vizinhança com conexões pobres com o resto da cidade, ou com serviços públicos deficientes geraria sentimentos de isolamento e confinamento. Além do mais, estes poderiam intensificar e transformar-se em sentimentos de estar aprisionado em um impasse para indivíduos que não podem sair, ou escapar. - por exemplo, devido a razões financeiras. E aprendemos da psiquiatria clínica que condições como estas podem levar a doenças físicas ou mentais sérias (World Health Organization, 2004, pp. 3-4, tradução nossa).

\section{Cenário nacional}

Para além do estabelecimento do direito à moradia em leis e programas habitacionais, no Brasil, a problematização sobre adequação das moradias parece ser decorrência da análise do déficit habitacional e integra um conceito mais amplo: o de necessidades habitacionais.
O conceito de necessidades habitacionais foi desenvolvido pela Fundação João Pinheiro (FJP) de Belo Horizonte, em 1995, em estudo que teve aceitação nacional, tornando-se referência metodológica para mensurar o déficit e retratar a situação habitacional no Brasil. De acordo com a FJP (2016), as necessidades habitacionais incluem demandas relacionadas com o déficit habitacional e com a inadequação dos domicílios. O "déficit habitacional" diz respeito à demanda por construção de novas moradias, ou seja, à ampliação do estoque existente. A "inadequação dos domicílios" concerne às especificidades dos domicílios que prejudicam a qualidade de vida de seus moradores. Vale notar que, no enquadre proposto pela FJP, o que está em pauta é o reverso da medalha: a inadequação dos domicílios - possivelmente por se tratar de análise de carências, e não de horizontes ideais. A adoção dessa metodologia inova e difere de outras análises de viés orientado aos interesses da indústria da construção civil e reduzem o problema da habitação popular exclusivamente à necessidade de construção de novas residências.

O déficit habitacional é calculado como a soma de quatro componentes: a) domicílios precários; b) coabitação familiar; c) ônus excessivo com aluguel urbano; e d) adensamento excessivo de domicílios alugados.

A inadequação das moradias é calculada a partir de cinco critérios: 1) carência de infraestrutura - domicílios que não dispõem de ao menos um dos seguintes serviços básicos: iluminação elétrica, rede geral de abastecimento de água com canalização interna, rede geral de esgotamento sanitário ou fossa séptica e coleta de lixo; 2) adensamento excessivo de domicílios próprios; 3) ausência e banheiro exclusivo; 4) cobertura inadequada; e 5) inadequação fundiária urbana.

Entre os critérios de inadequação de domicílios, a carência de infraestrutura é o que mais afeta os domicílios brasileiros e continua a ser um desafio importante a ser enfrentado pelos órgãos responsáveis pelos serviços básicos que compõem esse tipo de inadequação. Porém, a inadequação fundiária (imóveis em terrenos não legalizados) continua sendo o segundo critério de inadequação que mais afeta os domicílios particulares permanentes urbanos. Em 2014, 1,888 milhões de unidades no Brasil estavam em situação de inadequação fundiária urbana. Grande parte do problema se concentra nas regiões metropolitanas, que respondem por 50,5\% das 954 mil moradias nessa condição. Em termos absolutos, a inadequação fundiária 
está concentrada na região Sudeste, com 1,119 milhão de domicílios afetados. Desses, grande parte, $637 \mathrm{mil}$, está localizada em São Paulo, principalmente na sua região metropolitana. Vale apontar que, em 11 de julho de 2017, foi aprovada a Lei no 13.465 (Brasil, 2017), que institui uma nova política de regularização fundiária urbana. A lei é bastante controversa, pois altera várias legislações anteriores e introduz medidas que não têm o aval de especialistas da área.

A questão das necessidades habitacionais, nos dois eixos propostos pela Fundação João Pinheiro, é retomada por Raquel Rolnik em seu livro Guerra dos lugares: a colonização da terra e da moradia na era das finanças, publicado em 2015. Durante seis anos, de 2008 a 2014, Rolnik exerceu a função de relatora para o direito à moradia adequada na $\mathrm{ONU}$, o que a levou a realizar duas missões de observação por ano em países com diversos contextos, políticas e situações relacionadas à habitação. Apesar das diferenças entre países, a professora da Faculdade de Arquitetura e Urbanismo da Universidade de São Paulo (FAU-USP) pôde estabelecer nexos de um processo global que qualificou como financeirização das cidades, quadro que não exclui o Brasil. No caso brasileiro, a crise habitacional dos anos 1980 gerou uma situação de precariedade habitacional que reforçou as desigualdades existentes e criou novas desigualdades, apesar de inovações urbanísticas e do surgimento de novos empreendimentos imobiliários tanto nas áreas tradicionais da cidade como em áreas novas.

De acordo com Sampaio e Pereira (2003), hoje, cerca de $20 \%$ da área do município de São Paulo é ocupada de forma irregular por três mil loteamentos que abrigam precariamente cerca de três milhões de pessoas.

As casas precárias, autoconstruídas, continuam, assim, presentes nos loteamentos irregulares ou clandestinos como nas favelas, assim também nos lotes adquiridos ou na terra invadida. As diferenças entre ambas são praticamente nulas, principalmente naquelas feitas de alvenaria. Os lotes cada vez menores inviabilizam as possibilidades de aumentos e expansões horizontais através de reformas progressivas, comuns em épocas passadas. As casas são construídas uma ao lado da outra, espremidas, parede contra parede. A geminação que não procurada intencionalmente acaba acontecendo, resultando em situações precárias de habitabilidade, tanto em relação à iluminação e ventilação como a impossibilidade de abertura de janelas. Resta apenas a expansão vertical (Sampaio \& Pereira, 2003, p. 177).

Segundo o Relatório da Missão Conjunta da Relatoria Nacional e da ONU (Saule \& Cardoso, 2005), "Na cidade de São Paulo há mais imóveis vazios que famílias sem casa para morar. Os contrastes da maior cidade do país são tão grandes quanto sua população" (p. 30). Ou seja, há um grave problema relacionado à falta de moradia que vem sendo solucionado precariamente pela população, sobretudo das camadas mais pobres, por meio de opções variadas do que se consideram "moradias subnormais": cortiços, moradias em favelas e em lotes sem regularização fundiária.

Aproximadamente um milhão de pessoas habitam as favelas da cidade; de acordo com pesquisa do Centro de Estudos da Metrópole a velocidade de adensamento anual das favelas é cinco vezes a velocidade média do crescimento anual da população paulista. A grave situação dos moradores de cortiços (habitações coletivas multifamiliares precárias); dos loteamentos irregulares e precários, em especial aqueles localizados em área de proteção ambiental; dos moradores de rua e das áreas de risco completam o quadro de exclusão e de violação do direito de todos a ter um padrão de vida adequado, na cidade de São Paulo. Quase $80 \%$ das habitações precárias em que há coabitação familiar estão correlacionadas a famílias que ganham entre 0 e 5 salários mínimos, o que mostra que há enorme demanda por moradias adequadas, não atendida pelo mercado habitacional ou pelos programas governamentais. (Saule \& Cardoso, 2005, p. 30)

Não se trata de uma situação nova. Há um importante acervo de pesquisas de historiadores e urbanistas (Bonduki, 1998; Rolnik, 2015; Rubin \& Bolfe, 2014) que abordam o problema da habitação em São Paulo e mostram a dinâmica da exclusão perversa decorrente das práticas imobiliárias que,

levando à retração do padrão imobiliário extensivo (ou periférico) e, simultaneamente, à aceleração do padrão imobiliário intensivo (central ou de adensamento), reforçou as desigualdades existentes e criou novas desigualdades, apesar de 
inovações urbanísticas e do surgimento de novos empreendimentos imobiliários tanto nas áreas tradicionais da cidade como em áreas novas.... Deste ponto de vista mudou a maneira de segregar a população, tornando ainda mais desigual e precária as condições de habitação dos paulistanos. O que faz com que, para a maioria da população, a metrópole fique ainda mais excludente e torne mais distante a possibilidade de se obter uma moradia digna (Sampaio \& Pereira, 2003, p. 171).

\section{Da moradia adequada à moradia digna}

Vimos, no decorrer deste ensaio, que o ponto de partida contemporâneo para pensar moradia é o preâmbulo da Declaração dos Direitos Humanos que a inclui dentre os direitos básicos para respaldar um conceito fundamental do arcabouço de direitos o de dignidade.

Na Declaração Universal dos Direitos Humanos, o termo "dignidade" aparece no preâmbulo como primeira dentre as sete premissas que embasam a declaração: "Considerando que o reconhecimento da dignidade inerente a todos os membros da família humana e de seus direitos iguais e inalienáveis é o fundamento da liberdade, da justiça e da paz no mundo" (Nações Unidas, 1948). Está também no Artigo 1: "Todos os seres humanos nascem livres e iguais em dignidade $\mathrm{e}$ direitos. São dotados de razão e consciência e devem agir em relação uns aos outros com espírito de fraternidade" (Nações Unidas, 1948). Dignidade, portanto, neste contexto, é um atributo inalienável da própria condição de "ser humano". E, tendo por base o conceito de dignidade, uma diversidade de direitos, incluída aí a moradia.

Vimos também que o direito à moradia, a partir da Conferência de Vancouver na década de 1970 e a criação do UN-Habitat na década de 1980 passa progressivamente a ser qualificado a partir da definição do que seria moradia adequada. Porém não encontramos, nos documentos analisados, a expressão "moradia digna", embora, como já apontado, na tradução portuguesa da Ficha 21 conste "moradia condigna".

Em contraste, no Brasil, a expressão é encontrada em um importante documento: a Lei $\mathrm{n}^{\mathrm{o}}$ 11.124, de 2005, que definiu o Sistema Nacional de Habitação de Interesse Social (Brasil, 2005). Consta desta lei, como um dos objetivos Art. $2^{\circ}$ - inciso I: "Viabilizar para a população de menor renda o acesso a terra urbanizada e à habitação digna e sustentável" (Brasil, 2005). Contudo, como já apontado, neste documento não há definição do que seja "moradia digna”, visto que se trata basicamente de política norteadora de financiamento.

A expressão, todavia, se generalizou: há movimento sociais por moradia digna, jornadas promovidas pela defensoria de São Paulo e textos que situam moradia digna nos parâmetros já apresentados para caracterizar adequação das moradias. Desta monta, procurando entender por que caminhos a expressão passou a integrar os discursos sobre direito à moradia, nos deteremos na análise de dois documentos: o primeiro antecede a publicação da Lei que define o Sistema Nacional de Habitação de Interesse Social e é conhecido como Projeto Moradia, escolhido por ser amplamente citado em documentos posteriores, como o Plano Municipal de Habitação de São Paulo (São Paulo, 2003), e por ser a base da política habitacional a partir do governo de Lula. O segundo, mais recente, intitulado Direito à Moradia Adequada, foi publicado em 2013 durante o governo de Dilma Rousseff, e integra a série de cadernos Por uma cultura de direitos humanos.

O Projeto Moradia foi elaborado por integrantes de um conselho consultivo que buscou sintetizar o pensamento existente sobre a questão da habitação no Brasil e estabelecer as bases para a política de habitação que veio a ser implementada no governo de Lula. Foi este projeto que deu embasamento para a criação do Sistema Nacional de Habitação de Interesse Social pela Lei no 11.124 de 2005 (Brasil, 2005) e para as muitas ações instituídas durante o governo de Lula.

$\mathrm{Na}$ introdução, consta a afirmação de que "A idealização do Projeto Moradia parte da convicção de que o acesso à moradia digna é condição básica de cidadania" (Instituto Cidadania, 2000, p. 9). Em seguida, define-se o que é moradia digna: "Moradia digna é aquela localizada em terra urbanizada, com acesso a todos os serviços públicos essenciais por parte da população que deve estar abrangida em programas geradores de trabalho e renda" (Instituto Cidadania, 2000, p. 9). Ou seja, trata-se de afirmação de direito à cidadania plena.

O documento intitulado Direito à moradia adequada (Brasil, 2013) foi elaborado pela Secretaria de Direitos Humanos da Presidência da República (SDHPR), na gestão de Maria do Rosário Nunes, e fornece um panorama geral sobre o tema. Está estruturado em três partes. A primeira apresenta o conceito de moradia adequada, a legislação internacional e marcos legais brasileiros que dão respaldo ao 
conceito; a segunda parte concerne ao cenário brasileiro sobre condições de moradia; e a terceira se volta à afirmação do direito na perspectiva da população, ou seja, "Tudo que você precisa saber para garantir o direito à moradia" (Brasil, 2013, p. 64) .

No documento, como fizemos neste ensaio, há uma conexão intrínseca com os textos internacionais e nacionais, de modo que não surpreende que a tônica discursiva seja a questão da adequação das moradias. Sem contar as palavras do título e o sumário, considerando apenas o texto propriamente dito, a expressão "moradia adequada" é usada 89 vezes nas 74 páginas do documento. A qualificação "digna" é utilizada três vezes: para se referir à vida digna; à habitação digna, citando o conteúdo da Lei no 11.124 de 2005, que cria o SNHIS; e ao situar a problemática da habitação no Brasil, em referência a dados do Instituto Brasileiro de Geografia e Estatística (IBGE) sobre saneamento: "Os serviços de saneamento constituem a representação básica de uma moradia digna” (Brasil, 2013, p. 47).

Perguntamos: houve esvaziamento de uso da expressão "moradia digna" após o governo Lula? Obviamente, a resposta énegativa. Assistimos, em 2018, à realização da sexta edição da Jornada em Defesa da Moradia Digna, promovida pela Defensoria Pública do Estado de São Paulo. Curiosos em relação ao emprego da expressão, retomamos o processo de elaboração dessas jornadas. Os Anais da I Jornada em Defesa da Moradia Digna, realizada em 21 de fevereiro de 2007, estão disponíveis on-line, e consta do preâmbulo que relata o caminho da jornada a seguinte afirmação:

No entanto, é consenso que a habitação reflete, seja qual for a sua forma, o grau de cidadania alcançado ou permitido àquele que a ocupa. O conceito da moradia digna foi proposto com o objetivo de pautar a discussão habitacional pela questão do acesso à cidadania. Ou seja, a moradia digna amplia a discussão sobre quais são as premissas que formulam os padrões mínimos de habitabilidade necessários a uma habitação para que a conquista dessa seja também a conquista da cidadania. Sendo assim, a moradia digna busca conferir à habitação de interesse social um caráter universal, imprimindo, em cada diferente manifestação dessa moradia, saúde e educação, salubridade e conforto, segurança jurídica, serviços básicos (como água, luz, esgoto e coleta de lixo), transporte, trabalho, lazer e cultura (São Paulo, 2008, p. 9).
Ou seja, não parece haver estranhamento, no âmbito jurídico, para o uso da expressão "moradia digna". Como defendem Santos e Nunes Filho (2015):

Ao entender moradia como agente de satisfação das necessidades básicas (saúde e autonomia), surge uma nova pergunta o que deve ser entendido por um nível mínimo de satisfação no que concerne à moradia? A resposta a essa indagação aponta para a delimitação do conteúdo fático e jurídico do direito de morar à luz da dignidade da pessoa humana. Esse conjunto fático e jurídico determina o que convencionamos chamar de moradia digna (Não paginado).

\section{Considerações finais}

Nossa provocação, para concluir, é de que estamos assistindo a um processo de translação. Conforme proposta apresentada por Callon (1986), translação é um processo composto por quatro etapas: a problematização, o interessamento, a coordenação de papéis e a mobilização coletiva em prol do tema - no caso, o direito à moradia. $\mathrm{O}$ foco deste ensaio foi a problematização a partir da análise de documentos de domínio público. Esse processo se refere à construção da moradia como direito em contextos pautados por déficits habitacionais decorrentes de dinâmicas sociais e políticas que se fazem presentes em documentos internacionais e nacionais desde a promulgação da Declaração de Direitos Humanos. A evolução histórica da discussão sobre moradia leva a um consenso de que não basta ter um teto sobre a cabeça. O que está em pauta é a possibilidade de ter uma vida digna, que inclui ter onde morar, mas, sobretudo, implica a possibilidade de exercer cidadania. Essa discussão avança do estabelecimento de um direito ao direito a uma moradia adequada para, posteriormente, incorporar a moradia como um pré-requisito à cidadania na perspectiva de uma vida digna.

No caso analisado neste ensaio, todos os elementos que conformam o direito à moradia foram transladados e apropriados nas discussões sobre direitos humanos para compor uma nova categoria representativa: a moradia digna.

Em nossa análise, a problematização ocorreu porque houve uma aceitação tácita de que não são apenas agentes governamentais ou paragovernamentais que têm o poder de dotar dignidade 
às moradias. Segundo a Secretaria de Direitos Humanos da Presidência da República, há uma afirmação que possibilita refletir sobre o que seria uma vida digna:

No entanto, o ser humano não é só corpo físico. Aliás, o que o diferencia dos outros seres é exatamente a sua mente, a sua intelectualidade, a sua consciência, que também necessita de abrigo, necessita de lugar. Precisa de um local onde possa pensar sem interrupções, interagir com outros seres com privacidade e amar sem que seja observada, conservar suas memórias, expressar sua individualidade, viver sem máscaras, repousar depois de um longo dia (Brasil, 2013, p. 9).
Desse modo, as políticas públicas relacionadas à questão habitacional incorporaram as necessidades de adequação física da moradia e reconheceram seu caráter dignificante para a vida humana. Todavia a possibilidade de dotar de dignidade uma moradia depende necessariamente da apropriação do espaço pelos moradores. A incorporação dessa experiência no âmbito das políticas publicas habitacionais se mostra limitada.

Em suma, a polissemia do uso do adjetivo "digna" permite propor que moradores de habitações ditas precárias, que não atendem aos cânones de adequação habitacional, também têm agência. Podem, na medida de suas possibilidades, apropriar-se desses espaços, dando-lhes características que se coadunam com sua dignidade enquanto seres humanos.

\section{Referências}

Bernard, Y. (2005). Contribuição da psicologia ambiental para a política de construção de moradias. Psicologia USP, 16(1-2), 213-222. http://dx.doi.org/10.1590/S0103-65642005000100023

Bonduki, N. (1998). Origens da habitação social no Brasil. São Paulo, SP: Estação Liberdade.

Bonduki, N. (2015). Política habitacional e inclusão social no Brasil: Revisão histórica e novas perspectivas do governo Lula. In I. Dickmann, \& I. Dikmann (Orgs), A questão da habitação popular (pp. 141-173). Curitiba, PR: Base Editorial.

Brasil.(1988).ConstituiçãodaRepúblicaFederativadoBrasil.Brasília,DF:SenadoFederal.http://www.planalto.gov.br/ ccivil_03/Constituicao/Constituicao.htm

Brasil. (1992). Decreto $n^{o}$ 592, de 6 de julho de 1992. Promulga o Pacto internacional sobre direitos civis e políticos, adotado pela XXI Sessão da Assembleia Geral das Nações Unidas, em 16 de dezembro de 1966. http://www.planalto.gov.br/ccivil_03/decreto/1990-1994/d0592.htm

Brasil. (2001). Estatuto da Cidade: Leino 10.257, de 10 de julho de 2001. Regulamenta os arts. 182 e 183 da Constituição Federal, estabelece diretrizes gerais da política urbana e dá outras providências. http://www.planalto.gov.br/ ccivil_03/leis/leis_2001/110257.htm

Brasil. (2005). Lei $n^{o} 11.124$, de 16 de junho de 2005. Dispõe sobre o Sistema Nacional de Habitação de Interesse Social, cria o Fundo Nacional de Habitação de Interesse Social e institui o Conselho Gesto do FNHIS. https://www.camara.leg.br/proposicoesWeb/prop_mostrarintegra;jsessionid=C0F669056BF3C54B405994E 449A3DE67.proposicoesWebExterno2?codteor=656147\&filename=LegislacaoCitada+-PL+5207/2009

Brasil. (2013). Direito à Moradia Adequada. Brasília, DF: Secretaria de Direitos Humanos da Presidência da República.

Brasil. (2017). Lei no 13.465, de 11 de julho de 2017. Dispõe sobre a regularização fundiária rural e urbana, sobre a liquidação de créditos concedidos aos assentados da reforma agrária e sobre a regularização fundiária no âmbito da Amazônia Legal. http://www.planalto.gov.br/ccivil_03/_ato2015-2018/2017/lei/113465.htm

Callon, M. (1986). Some elements of a sociology of translation: domestication of the scallops and fishermen of St. Brieuc Bay. In J. Law (Org.), Power, action and belief: A new sociology of knowledge? (pp. 196-233). London: Routledge, 1986.

Castro, P. (2005). Crenças e atitudes em relação ao ambiente e à natureza. In L. Soczka (Org.), Contextos humanose psicologia ambiental (pp. 169-201). Lisboa: Fundação Calouste Gulbenkian.

Chapin, F. S. (1951). The psychology of housing. Social Forces, 30(1), 11-15. https://dx.doi.org/10.2307/2571735

Ferreira, M. R. (2004). Problemas ambientais como desafio para a psicologia. In H. Günther, J. Q. Pinheiro, \& R. S. L. Guzzo (Orgs), Psicologia ambiental: Entendo as relações do homem com o seu ambiente (pp. 17-30). São Paulo, SP: Alínea. 
Franco, R. F., \&Van Stralen, C. J. (2012). O espaço de habitação e sua importância para a produção de subjetividade. Psicologia em Revista, 18(3), 402-419. https://dx.doi.org/10.5752/P.1678-9563.2012v18n3p402

Fundação João Pinheiro. (2016). Déficit habitacional no Brasil 2013-2014. Belo Horizonte, MG: FJP.

Instituto Cidadania. (2000). Projeto Moradia. São Paulo, SP: Instituto Cidadania.

Nações Unidas. (1948). Declaração Universal dos Direitos Humanos. Brasília, DF: Ministério das Relações Exteriores, Ministério da Justiça. https:// unesdoc.unesco.org/ark:/48223/pf0000139423

O Globo. (2018, 3 de maio). Fotos mostram regras de convivência no prédio que desabou em SP. https://oglobo.globo.com/ brasil/fotos-mostram-regras-de-convivencia-no-predio-que-desabou-em-sp-22647867

Rabinovich, E. P., \& Carvalho, A. M. A. (2001). Modo de morar e modo de cuidar: uma proposta de tipologia. Psicologia: Ciência e Profissão, 21(2), 74-85. https://dx.doi.org/10.1590/S1414-98932001000200009

Rolnik, R. (2015). Guerra dos lugares: A colonização da terra e da moradia na era das finanças. São Paulo, SP: Boitempo.

Rubin, G. R., \& Bolfe, S. (2014). O desenvolvimento da habitação social no Brasil. Ciência e Natura, 36(2), 201-213. http://dx.doi.org/10.5902/2179460X11637

Sampaio, M. R. A., \& Pereira, P. C. X. (2003). Habitação em São Paulo. Estudos Avançados, 17(48), 167-183. http://dx.doi.org/10.1590/S0103-40142003000200014

Santos, K. C. C., \& Nunes Filho, M.S. (2015). Políticas públicas sociais aplicadas ao direito à moradia digna. Contribuciones a las Ciencias Sociales, 27. Não paginado. http://www.eumed.net/rev/cccss/2015/01/moradia-digna.html

São Paulo. (2003). Plano Municipal de Habitação (versão para debate). São Paulo, SP: Secretaria da Habitação e Desenvolvimento Urbano.

São Paulo. (2008). I Jornada em Defesa da Moradia Digna. São Paulo, SP: Defensoria Pública do Estado de São Paulo.

Saule, N., Jr., \& Cardoso, P. M. (2005). O Direito à moradia no Brasil. Relatório da Missão Conjunta da Relatoria Nacional e da ONU 29 de maio a 12 de junho de 2004. São Paulo, SP: Instituto Pólis.

Segaud, M. (2016). Antropologia do espaço: Habitar, fundar, distribuir, transformar (E. R.R. Heneault, Trad.). São Paulo, SP: Edições SESC.

Spickard, J. V. (2017). The Origins of the Universal Declaration of Human Rights. InSPIRe @ Redlands. https://inspire.redlands.edu/working/ 1

Spink, M. J. (2018). Viver em áreas de risco: Reflexões sobre vulnerabilidade socioambientais. São Paulo, SP:Terceiro Nome.

Spink, P., Ribeiro, M. A. R., Conejo, S. P., \& Souza, E. (2014). Documentos de domínio público e a produção de informações. In M. J. Spink, J. Brigagão, V. Nascimento, \& M. Cordeiro (Orgs.), A produção de informação na pesquisa social: Compartilhando ferramentas (pp. 207-228). Rio de Janeiro, RJ: Centro Edelstein de Pesquisas Sociais.

United Nations. (1945). United Nations Charter: Preamble, purposes and principles. San Francisco: UN. http://www.un-documents.net/ch-ppp.htm

United Nations. (1991). General Comment no 4: The Right To Adequate Housing (Art. 11 (1) of the Covenant). Geneva: Office of The High Commissioner for Human Rights. https://www.refworld.org/pdfid/47a7079al.pdf

United Nations. (2009). Fact Sheet $n^{\circ} 21$ : The right to adequate housing. Geneva: Office of the High Commissioner for Human Rights (OHCHR). http://www.refworld.org/docid/479477400.html

United Nations Educational and Cultural Organization. (1949). Appendix II: The grounds of an international Declaration of Human Rights. In United Nations Educational and Cultural Organization, Human rights: Comments and interpretations. A Symposium edited by Unesco (pp. 258-272). New York: Columbia University Press.

World Health Organization. (2004). Review of evidence on housing and health. Budapest: WHO.

\section{Mary Jane Paris Spink}

Graduação em Psicologia pela Universidade de São Paulo (1969) e doutorado em Psicologia Social pela London School of Economics and Political Science (1982). Professora titular da Pontifícia Universidade Católica de São Paulo, do Programa de Estudos Pós-Graduados em Psicologia Social, São Paulo - SP. Brasil.

E-mail:mjpspink@gmail.com

(1) https://orcid.org/0000-0003-1672-505X 


\section{Mário Henrique da Mata Martins}

Graduação em Psicologia pela Universidade Federal de Alagoas (2011) e doutorado em Psicologia Social pela Pontifícia Universidade Católica de São Paulo (2018). Pesquisador da Fundação Getulio Vargas, do Centro de Estudos em Administração Pública e Governo, São Paulo - SP. Brasil.

E-mail: martins.mariodamata@gmail.com

(D) https://orcid.org/0000-0002-1370-300X

\section{Sandra Luzia Assis Silva}

Graduação em Psicologia pela Universidade do Grande ABC (2013) e mestrado em Psicologia Social pela Pontifícia Universidade Católica de São Paulo (2016). Doutoranda na Pontifícia Universidade Católica de São Paulo, do Programa de Estudos Pós-Graduados em Psicologia Social, São Paulo - SP. Brasil.

E-mail: sandralassis@hotmail.com

(D) https://orcid.org/0000-0002-1290-6542

\section{Simone Borges da Silva}

Graduação em Psicologia pela Universidade Nove de Julho (2011), especialista em Saúde Coletiva pela Universidade Federal de São Paulo (2014) e mestre em Psicologia Social pela Pontifícia Universidade Católica de São Paulo (2017). Psicóloga da Associação Saúde da Família, atuante no Centro de Atenção Psicossocial III Adulto, São Paulo - SP, Brasil. E-mail: simonee.borges@gmail.com

(D) https://orcid.org/0000-0003-1204-656X

Esta pesquisa contou com o financiamento do Conselho Nacional de Desenvolvimento Científico e Tecnológico (CNPq) via bolsa produtividade 1A concedida à Mary Jane Paris Spink (processo 304602/2016-7), da Fundação de Amparo à Pesquisa do Estado de São Paulo (FAPESP) via bolsa de pós-doutorado concedida à Mário Henrique da Mata Martins (processo 2019/06595-2) e da Coordenação de Aperfeiçoamento do Pessoal de Nível Superior (CAPES), via bolsa de doutorado concedida à Sandra Luzia Assis (processo 88887.149687/2017-00)

Endereço para envio de correspondência:

Pontifícia Universidade Católica de São Paulo. Programa de Estudos Pós-Graduados em Psicologia Social. Rua Monte Alegre, 984, Perdizes. CEP: 05014-901. São Paulo - SP. Brasil.

Recebido $11 / 06 / 2018$

Aceito 18/03/2019

Received $11 / 06 / 2018$

Approved 18/03/2019

Recibido 11/06/2018

Aceptado 18/03/2019

Como citar: Spink, M. J. P., Martins, M. H. M., Silva, S. L. A., \& Silva, S. B. (2020). O Direito à Moradia: Reflexões sobre Habitabilidade e Dignidade. Psicologia: Ciência e Profissão, 40, 1-14. https://doi.org/10.1590/1982-3703003207501

How to cite: Spink, M. J. P., Martins, M. H. M., Silva, S. L. A., \& Silva, S. B. (2020). The Right to Adequate Housing: Considerations about Habitability and Dignity. Psicologia: Ciência e Profissão, 40, 1-14. https://doi.org/10.1590/1982-3703003207501

Cómo citar: Spink, M. J. P., Martins, M. H. M., Silva, S. L. A., \& Silva, S. B. (2020). El Derecho a la Vivienda: Reflexiones sobre Habitabilidad y Dignidad. Psicologia: Ciência e Profissão, 40, 1-14. https://doi.org/10.1590/1982-3703003207501 